\title{
Ultrahigh Resolution EDX Spectrum Imaging: Nuclear Materials Applications
}

\author{
E. Francis, S. Haigh, M. G. Burke, A. Gholinia and M. Preuss \\ Materials Performance Centre, School of Materials, University of Manchester, Manchester UK
}

Key to understanding the behaviour of materials is knowledge of the microstructure, since it determines material performance and properties. In particular, the fine-scale microstructure can have dramatic effects on the oxidation, corrosion, and environment-sensitive behaviour of materials. Materials for nuclear power applications can exhibit significant variations in behaviour that are related to the microstructures developed during alloy processing and thermal treatment. Thus, as demands on material performance increase, it is frequently necessary to understand the ultrafine-scale microchemical changes that develop in the material during processing or during operation. The FEI Titan G2 80/200 S/TEM with ChemiSTEM ${ }^{\mathrm{TM}}$ technology at the University of Manchester is being used to address such issues in a variety of materials, particularly those alloys used in nuclear power generation. Two such examples are presented: Nanoscale segregation in low Sn ZIRLO, and ultrafine segregation at an environmentallyassisted crack-tip in austenitic stainless steel. Both materials were analysed in the Titan G2 80/200 $\mathrm{S} / \mathrm{TEM}$ operated at $200 \mathrm{kV}$.

Low Sn ZIRLO (1wt $\% \mathrm{Nb}-0.7 \mathrm{wt} \% \mathrm{Sn}-0.1 \mathrm{wt} \% \mathrm{Fe}-$ bal $\mathrm{Zr})$ : Iron plays an important role in the performance of zirconium alloys with regard to corrosion as well as under irradiation. Because the solubility of iron is low in zirconium, second phase precipitates (e.g Zr-Fe-Nb) form, which greatly reduces that amount of iron in the matrix. During irradiation iron is believed to go out of these second phase particles and into solution in the matrix. A previous study of non-irradiated ZIRLO using 3D atom probe analysis had shown iron segregation at the grain boundaries [1]. In this study, conventional electropolished TEM specimens were analysed. Figure 1a contains a HAADF image of a beta-Nb precipitate in the $\mathrm{Zr}$ matrix. Figure $1 \mathrm{~b}$ shows a combined spectrum image of $\mathrm{Zr}, \mathrm{Fe}$ and $\mathrm{Nb}$, with readily observable Fe segregation to the precipitate/matrix interface. High resolution EDX microanalysis has also provided clear evidence of iron in $\mathrm{Zr}-\mathrm{Nb}-\mathrm{Fe}$ second phase precipitates in low Sn ZIRLO. In addition, it was possible to detect iron segregation to grain boundaries as well as to the interface of beta$\mathrm{Nb}$ second phase precipitates.

Austenitic Stainless Steel: The tip of an environmentally-assisted crack (EAC) in Type 304 stainless steel was extracted using an FEI Novalab 660 Dual Beam FIB. The oxide-filled crack consisted of both $\mathrm{Cr}_{2} \mathrm{O}_{3}$ and $\mathrm{Fe}-\mathrm{Ni}$ ferrite spinel. Of particular importance was the assessment of sulphur within the crack enclave, due to the dissolution of $\mathrm{MnS}$ inclusions in the elevated temperature primary water environment. The HAADF image of a portion of the crack-tip is shown in Figure 2 (a). The EDX spectrum images obtained confirmed the presence of the various oxides within the crack. In addition, an irregular distribution of an ultrafine sulphur-enriched layer (approximately 4-5 $\mathrm{nm}$ in width) was detected at the oxide/metal interface of the crack wall. Such fine-scale enrichments would be exceeding difficult, if not impossible, to detect with conventional FEG analytical electron microscopes. 

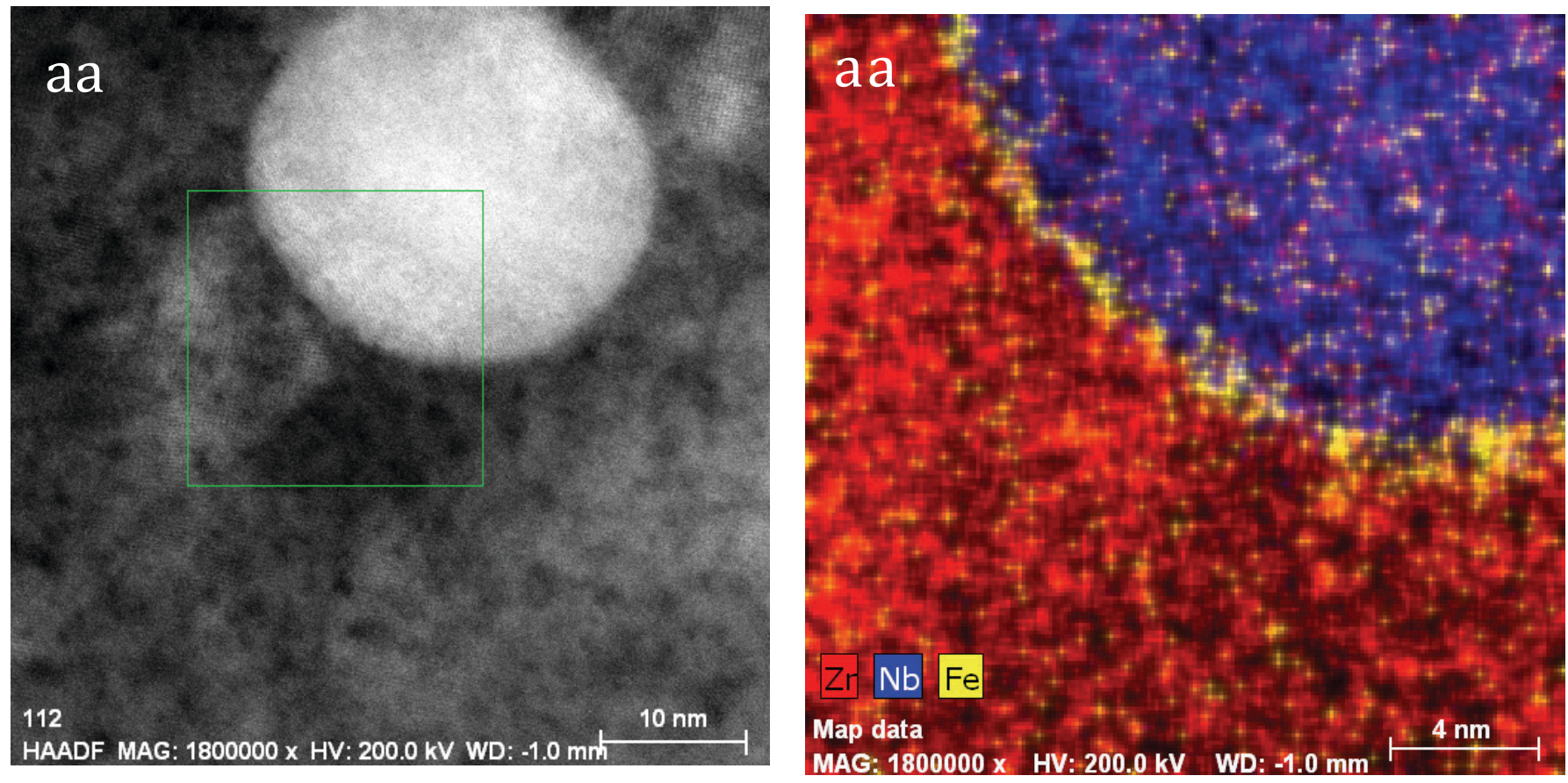

Figure 1. (a) HAADF image of precipitate in low Sn Zirlo; (b) EDX spectrum image showing $\sim 1 \mathrm{~nm}$ Fe enrichment at the interface of a beta-Nb precipitate in low Sn Zirlo.
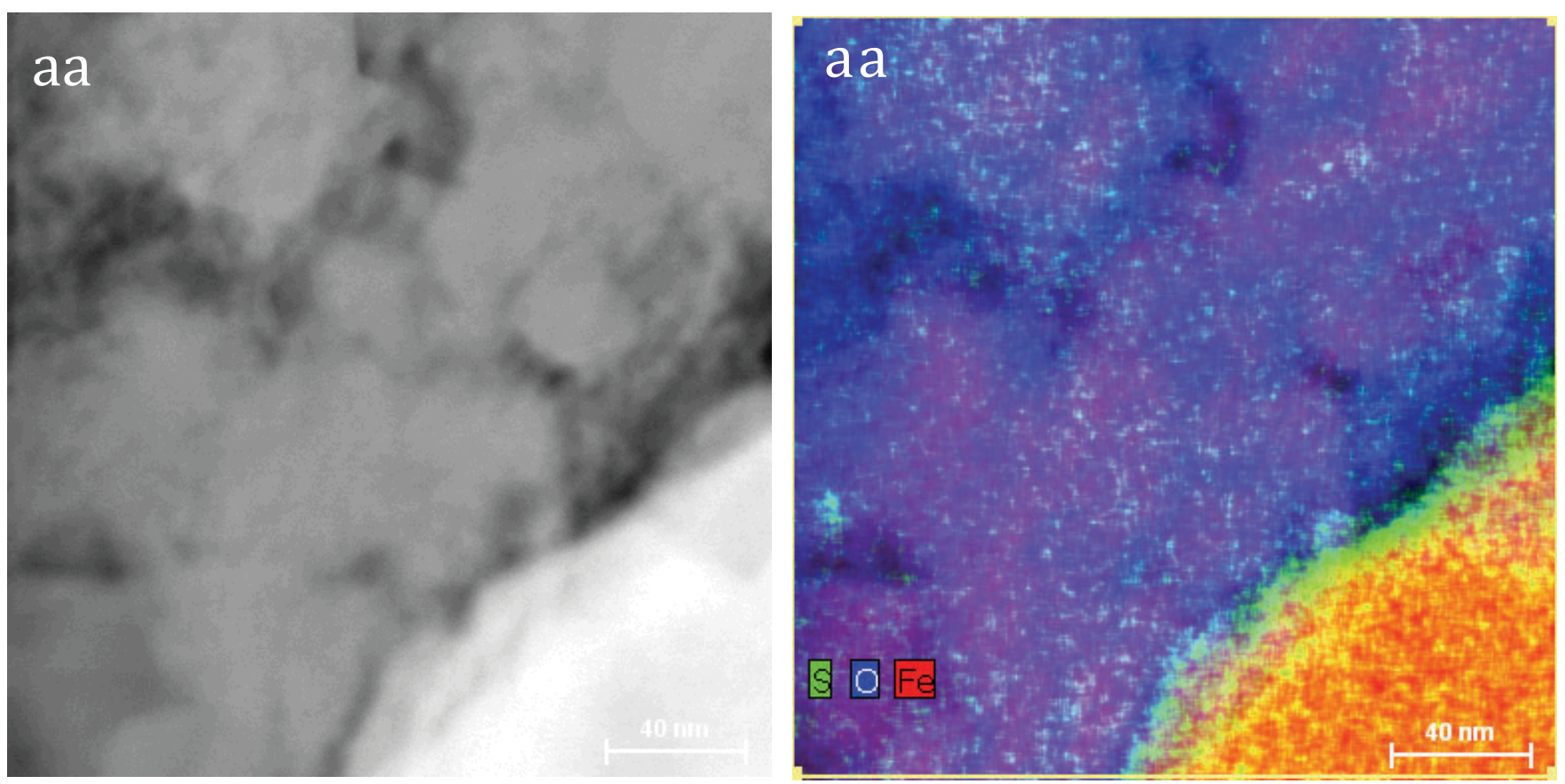

Figure 2. (a) HAADF image of an oxide-filled crack in Type 304 austenitic stainless steel; and (b) the EDX spectrum image showing the oxide-filled crack with an fine $(\sim 5 \mathrm{~nm})$ layer of $S$ and the crack tip.

Reference:

[1] [Hudson D, Smith GDW. Scripta Materialia 2009;61:411 